\title{
The Recreational Identity Assessment of the Cultural Landscape Management in the Miaoli County, Taiwan
}

\author{
Shih-Chung Lu and Kuei-Yang Wu
}

\begin{abstract}
With the need of cultural heritage conservation, the issue of cultural landscape management becomes one of the main environmental problems. Based on the literature review, the cultural landscape and public perception are the most two main factors to influence the sustainability of tourism development at Taiwan. Therefore, the study focused on the recreational identity for understanding of the cultural landscape at Miaoli. It also pays attention to survey the recreational identity for the satisfactions for the present recreational environment and landscape quality. For the research process, there are $\mathbf{5 7 4}$ valid questionnaires by using the face to face survey and structural questionnaires, and the pre-test is suitable for the final survey. The major results show that the government need pay more attention for the improvement of tourism marketing and its efficiency, although the people feel more satisfied with the late improvement strategies, including new cultural landscape promotion. In addition, the public has more abnegation for the future landscape preferences and tour planning, and those were able to influence tourists' revisiting willingness of tourists. Otherwise, they have general acceptance and the identification of the policy supporting for cultural landscape management. However, more than $70 \%$ people report the government cannot show the enough information to gain the public supporting by mass media, and the situation impacts the reputation of Miaoli County.
\end{abstract}

Index Terms-Recreational identity, miaoli county, cultural landscape management, contingent valuation method.

\section{INTRODUCTION}

With the trend of sustainable development and globalization, the issue of cultural landscape use becomes one of the main environmental problems. Many countries or cities try to improve the conservation of cultural landscape and look forward to an alternative way to overcome the conflict between development and protection [1]-[4]. Miaoli County was in the tourism crisis, especially cultural landscape. It owned a lot of traditional industries and cultural heritages, but the sites were not able to promote the local development. Then, the local government cannot exchange the cultural landscape to the practical income, so that the local government met some serious finance problems for the more serious predicament. Therefore, the possible way for the solution of finances was to increase the

Manuscript received November 11, 2016; revised March 1, 2017. This research is supported by the Ministry of Science and Technology, Taiwan. (MOST 105-2420-H-239-002-).

Shih-Chung Lu is with the Department of Architecture and Landscape Design, Nunhua University, Taiwan (e-mail: sclu@nhu.edu.tw)

Kuei-Yang Wu is with the Department of Architecture, National United University, Taiwan (e-mail: kyw@nuu.edu.tw) tourists for its rich cultural landscape resources [5]-[7].

Based on the pre-study by using the in-depth interview, the cultural landscape management and recreational identity are the most two main factors to influence the sustainability of Miaoli county. The situation shows that the cultural landscape plays an important role for the recreational identity, and the related policies need public supporting and improved the related income.

Therefore, the study focuses on the recreational identity for better understanding of the cultural landscape, including cultural development, heritage conservation and religious temples. It also pays attention to survey the recreational identity for the satisfactions for the present tourists and the future possible tourists. The user willingness to pay for the sustainable cultural landscape use is valued by using the contingent valuation method and the results are shown as the public supporting standard for the possible strategies.

\section{METHOD}

\section{A. Theoretical Design}

The theoretical basis for the present study is that behavior can be predicted well by respondent's behavioral intentions which are explained by conviction, communal criterion and attitude. For the show of behaviors and attitudes, the content of questionnaire was suitable to cover the evaluations for reliability and validity. Selective captures owned the evaluation of the behavior by respondents which matter to the individual under study. Attitude represents the ability of an individual to actually engage in the behavior under study. As such it captures hindering factors.

The value for each of these three dimensions is computed by combining two underlying aspects: in the case of conviction, one aspect is whether the individual thinks that the behavior will have certain consequences. The effect of communal criterion on behaviors consists of the individual's assessment of important peer's evaluation of the behavior and the extent to which it matters what peers think. Attitude is composed from the assessment of various factors facilitating or inhibiting the behavior and the extent to which this is the case. Based on the literature review the study framework is following as Fig. 1.

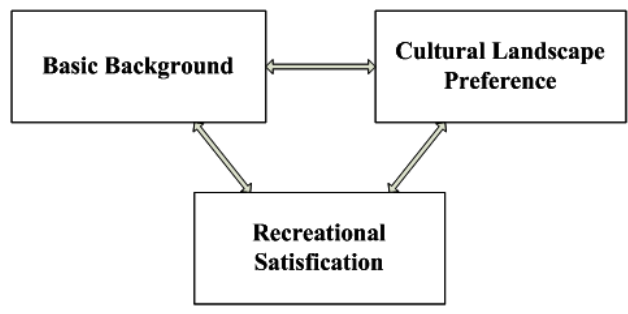

Fig. 1. Recreational satisfaction. 


\section{B. Research Sites}

Miaoli County is located at the north-central part of Taiwan. Its north and northeast side of it is connected to Hsinchu County. The south and east side of it is connected to Taichung County by Ta-an river and Hsuehshan (Mountain) Range. As for the west side, it is connected to Taiwan Strait. Daba peak is located at Tai-an Township's Mei-yuan village and it is the most east side of Miaoli. Miaoli County's most west and south sides are Yuan-li Township's Fang-li coastline and the south part of Jhuo-lan Township's Nei-wan Village. As to the most north side of Miaoli, it is the north part of Jhunan Township's Ci-ding Village. The county center is located in the Fonglin Village of Shihtan Village. The north to the south of Miaoli County is fifty kilometers and the breadth of Miaoli County is 50 kilometers and The east to the west of Miaoli County is 64 kilometers. The coastline of Miaoli County is almost 50 kilometers from the northern $\mathrm{Ci}$-Din of Chunan to the southern Fangli Coast of Chunan. It makes the square of Miaoli looks like a diamond. Most of terrains of Miaoli County are mountain regions and wolds. Therefore, people always called Miaoli is a "Mountain Town". Because of the alluvial fan of Hsuehshan Range has been corroded by rivers, the terrain of Miaoli County has been divided into several wolds and tablelands. There area several rivers shuttle through the different kind of terrains. which makes many different sceneries to Miaoli County [8].

\section{Contingent Valuation Method}

The comprehensive perception of cultural landscape use was abstractive and not means for transaction. For the valuation of those kinds of none-market resources, CiriacyWantrup (1947) first proposed the Contingent Valuation Method (CVM) as a survey-based economic technique [9]. This method offers an imaginative pricing system to trace the demand curve for a public good unavailable from market data [10]. This system referred to as a preference model helps us recognize what are worth to people [11]. Portney (1994) argued that the approach of CVM must first "contain a scenario or description of the (hypothetical or real) policy or program for the respondents to value or vote upon [12]." Second, "the survey must contain a mechanism for eliciting value or a choice from the respondents", typically with open-ended questions such as how much money people would be willing to pay for ...? Two guidelines for the application of CVM are that personal interviews, rather than telephone interviews, should be conducted to improve face validity, and follow-up questions should be asked to ensure that respondents understand the choices they are being asked to make and to discover the reasons for their answers. These two guidelines were followed in the study. CVM is now used in research throughout the world in a variety of fields, including transportation, sanitation, health, the arts, education and environmental studies [13]. For general respondents, CVM offers a simple way for them to express their degrees of preference.

The questionnaire used in the study measured a 10 -item group for "Cultural landscape preference", one 11-itemgroup for "recreational satisfaction," and a 10-item group for "Basic background." The items, "Willingness to pay," "Age" and "Annual Income", were set to be open-ended as interval measures. They were interviewed through the qualitative process and acted as the "subject matter expert rater" to check every item of the questionnaire in a yes-orno referendum format. Each qualified item was approved by more than half of the panelists. To make sure the survey was clear and understandable; it was given as a pilot study to 106 dwellers that live respectively. The reliability and internal consistency of the survey were assessed by using Cronbach's coefficient alpha.

\section{Questuinnaire Design and Sampling}

The questionnaire was followed as the research framework to support the content. It was divided into four parts, including cultural landscape preference, recreational satisfaction, willing to pay, and demographic attributes. Based on the pre-test, the factors owned lower factor loadings were ignored. Then, the total factors are 33 (see Table I).

Because the aim of the study is to explore the role of communal criterion and attitude on water-related behavioral intentions-as opposed to making statements about population proportions who share certain perspective or intentions-it is not necessary for the sample to be representative. Rather, it is important that input from a highly heterogeneous group of respondents is captured.

The face to face survey was conducted in January, 2014, through 574 questionnaires using five-point Likert-type scale designed to identify respondents' preferences regarding the sustainable cultural landscape use. Interviewers had been trained previously and were ready to administer the surveys. Survey participants were interviewed through a convenient sampling approach in the Taichung metropolitan areas with sample sizes conforming to the population ratio of each region. Respondents were asked to complete every item in the questionnaire. A total of 32 respondents stated that they didn't have time to finish the survey or refused to complete it, and 30 stated that they had never known the sustainable water use, leaving a qualified sample size of 512 , or a response rate of $89.2 \%$. T-test and ANOVA tests were used to identify the differentiation of different groups. Principal component analysis, the contingent valuation method, and general linear regression analysis with the stepwise method were used to analyze the effects of the perception factors and reveal a preference model.

TABLE I: THE CONTENT OF QUESTIONNAIRE

\begin{tabular}{clc}
\hline \hline Group & \multicolumn{1}{c}{ Main Content } & Measure \\
\hline & $\begin{array}{l}\text { 1.Identification for weakness of } \\
\text { cultural landscape at Taiwan }\end{array}$ & Interval \\
\cline { 2 - 3 } & $\begin{array}{l}\text { 2. Present cultural landscape use } \\
\text { ways }\end{array}$ & Interval \\
\cline { 2 - 3 } 3.Preference for government policy & Interval \\
\cline { 2 - 3 } Cultural & $\begin{array}{l}\text { 4.Acceptance of reclaimed cultural } \\
\text { landscape }\end{array}$ & Interval \\
\cline { 2 - 3 } preference & $\begin{array}{l}\text { 5.Preference for cultural landscape } \\
\text { connections }\end{array}$ & Interval \\
\cline { 2 - 3 } & $\begin{array}{l}\text { 6.Preference for future use } \\
\text { 7. Safety of cultural heritage }\end{array}$ & Interval \\
\cline { 2 - 3 } & $\begin{array}{l}\text { 8.Acceptance of the amount of } \\
\text { present information }\end{array}$ & Interval \\
\cline { 2 - 3 } & $\begin{array}{l}\text { 9.Who can influence the } \\
\text { acceptance of cultural landscape } \\
\text { use }\end{array}$ & Nominal \\
\hline
\end{tabular}




\begin{tabular}{|c|c|c|}
\hline & $\begin{array}{l}\text { 10.Reasons to influence the } \\
\text { acceptance of cultural landscape } \\
\text { use }\end{array}$ & Nominal \\
\hline \multirow{11}{*}{$\begin{array}{l}\text { Recreational } \\
\text { satisfaction }\end{array}$} & 11.Satisfaction of policy & Interval \\
\hline & $\begin{array}{l}\text { 12.Satisfaction of local } \\
\text { government policy }\end{array}$ & Interval \\
\hline & 13.Rationality of charge fee & Interval \\
\hline & 14.Preference of charge fee & Interval \\
\hline & 15.Order of cultural landscape use & $\begin{array}{l}\text { Prior } \\
\text { Order }\end{array}$ \\
\hline & $\begin{array}{l}\text { 16.Preference in Public } \\
\text { Construction }\end{array}$ & Interval \\
\hline & $\begin{array}{l}\text { 17.Preference in economic } \\
\text { development }\end{array}$ & Interval \\
\hline & $\begin{array}{l}\text { 18.Preference in industrial } \\
\text { development }\end{array}$ & Interval \\
\hline & 19.Preference in recreational use & Interval \\
\hline & 20.Perception of present policy & Interval \\
\hline & $\begin{array}{l}\text { 21. Acceptance of government for } \\
\text { cultural landscape conservation }\end{array}$ & Interval \\
\hline \multirow[b]{2}{*}{$\begin{array}{l}\text { Willing to Pay } \\
\text { and Following } \\
\text { up Question }\end{array}$} & $\begin{array}{l}\text { 22.Willingness to Pay(in NT\$ per } \\
\text { year) for cultural landscape use }\end{array}$ & $\begin{array}{c}\text { Interval } \\
\text { (open ended ) }\end{array}$ \\
\hline & $\begin{array}{l}\text { 23. Willingness to Pay(in NT\$ per } \\
\text { year) for maintaining the same } \\
\text { using level without changing habits }\end{array}$ & $\begin{array}{c}\text { Interval } \\
\text { (open ended ) }\end{array}$ \\
\hline \multirow{10}{*}{$\begin{array}{l}\text { Demographic } \\
\text { Attributes }\end{array}$} & 24.Gender & Nominal \\
\hline & 25.Residential area & Nominal \\
\hline & 26.Age & Interval \\
\hline & 27.Education & Nominal \\
\hline & 28.Occuption & Nominal \\
\hline & 29.Family Income & Interval \\
\hline & 30.Annual Income & Interval \\
\hline & $\begin{array}{l}\text { 31.Cultrual professional } \\
\text { background }\end{array}$ & Nominal \\
\hline & 32.Origin of information & Nominal \\
\hline & 33.Information enough level & Interval \\
\hline
\end{tabular}

\section{B. Identity of Clutural Landscape}

A total of $30.79 \%$ (most agreed) and $29.42 \%$ (agreed) of the respondents listed their agreement for the fact that there is lack of tourism resources at Miaoli county. Most of them feel they have better ways for recreational experience than before, and not satisfy the government related policy.

Respondents were asked how they felt about using cultural landscape. The question aimed at eliciting general conviction, because it was not totally suitable that the cultural landscape was used in the tourism development. The unconditional acceptance of cultural landscape was higher than expected given the low acceptance levels reported in previous quantitative studies. One third of the respondents said that would have no problem about the cultural landscape with tourism development and another 26 would be willing to use it if a condition would be met to arrive the conservation quality. Only a small number of respondents stated that they would require more information. However, as will be shown later, the general level of recognition about cultural landscape identity is extremely low in the population. 8 percent were undecided and expressed feelings of caution and skepticism. 18 percent would not understand the cultural landscape management within the tourism development.

One third of respondents denied that anyone would have any effect at all; one fifth stated that information provided by expert would be influential. Other, less frequently mentioned, sources of effect included experts in general, media, previous users, the tourist authority, local government, the local and general public, workers in the related department and one respondent from Miaoli reported that their children offered more information form schools. It can be concluded that while a wide range of respondents affect their conviction towards cultural landscape use as well as their behavioral intention expert has a special role to play in the information transfer relating to landscape sources.

Interestingly, when asked who effected their decision not to use cultural landscape respondents did not provide the same responses, indicating that supportive information and critical information are likely to come from different communal contexts. One fifth of respondents believe that nobody would affect them. Twelve percent state that friends and family would play a major role, followed by only $8 \%$ who named expert in the non-using context. Experts (including some TV stars) were named by $4 \%$ each. Other one-off statements included the public, the government, the tourist authority, media, politicians, prior users and public tourist experts. Factual recognition was mentioned more frequently in the context of influencing respondents to use cultural landscape resources; however, opinions appear to play a bigger role in convincing them to be cautious and not to use cultural landscape.

\section{Satisfaction and Acceptance for Cultural Landscape}

More than $60 \%(40.63 \%+21.09 \%)$ respondents illustrate the un-satisfaction for the present policy of cultural landscape use, and they also cannot satisfy the local policy from local government. The respondents from Miaoli prove they feel much better for the cultural landscape use although the site has the worst related policy before. For the charge fee, the conflict was existed naturally, because the 
respondents show they are wondering the rationality of charge fee, but they do not expect the increase of charge fee. For the prior order of landscape resource use, most of them explain the domestic use is more important than others, economic use, industrial use and public construction, and the individual preference results are proved as well. Overall, the respondents cannot identify the present policy, no matter center or local government.

Most of the future strategies, supporting cultural landscape with tourist development, are confirmed by most respondents, and the supporting standard are more than $60 \%$, expect for the increase of charge fee (only 32.03\%). The increase of viewpoints and tour arrangement earn even more than $70 \%(73.05 \%$ and $70.31 \%)$ supporting, and the nearly $65 \%$ respondents show they accept more brassbound policy for cultural landscape management. Otherwise, for the respondents at the Sanyi township, they have more acceptances for the cultural landscape with tourism development, because they have done so.

\section{The Inter-Relationship between Demographic Attributes and Identity of Cultural Landscape}

Through the analysis, several variables in demographic attributes are related with some items, belonging to the perception of cultural landscape use. For the residential area, the "Present cultural landscape use ways", "Preference for government policy", "Acceptance of cultural landscape", "Preference not for close-to-body use of cultural landscape", and" Preference for close-to-body use of reclaimed cultural landscape" have a significantly correlation, and the results show different metropolitan area have different identification for the cultural landscape use. Moreover, "Education" is significant correlated with "Identification for lack of cultural landscape resources at Taiwan", "Preference for "close-to-body" use of cultural landscape", and "Safety of reclaimed cultural landscape", and then the situation illustrates the respondents with higher education care more about the safety for the cultural landscape and its extension issues. "Professional background" is significantly correlated with "Preference for government policy", "Acceptance of cultural landscape", "Who can influence the acceptance of cultural landscape", and "Reasons to influence the acceptance of cultural landscape", so that the environmental professional background may have some differences for cultural landscape use perception. By using Pearson product-moment correlation, "Acceptance of cultural landscape", "Preference not for close-to-body use of cultural landscape and "Preference for close-to-body use of cultural landscape" have significantly positive correlations with the both of income is significant respectively, and the results can match the education partly.

\section{E. The Inter-Relationship between Demographic Attributes and Acceptance for Cultural Landscape}

For the correlation analysis, some variables in demographic attributes are related with some items in the policy perceptions. "Residential area" is significantly correlated with "Satisfaction of policy", "Satisfaction of local government policy", "Rationality of cultural landscape use", "Preference of cultural landscape use", "Order of cultural landscape use", "Preference in Public Construction", "Preference in economic development" and "Acceptance of government for cultural landscape conservation", and it means the different living city should have different problems and regulations for cultural landscape use to influence the public identification. In addition, there is a significant correlation between "Education" and some of them, such as "Satisfaction of policy", "Satisfaction of local government policy", "Preference of cultural landscape use", "Preference in economic development", "and Preference in industrial development". Comparison with Residential area, both of their results are similar, and it may be based on the different population structures in the different cities. The "Environmental professional background" and the items of both of income are also showed as the situation.

\section{F. Willingness to Pay}

Based on the WTP approach, the model of public preferences regarding cultural landscape use was shown as below (with un-standardized coefficients) by using simple linear regression analysis and stepwise regression analysis: (see $\operatorname{Eq}(1), \operatorname{Eq}(2))$

1) Normal Model (simple linear regression, see Table I)

$\mathrm{WTP}=1023+16.84 \times(1)+1.72 \times(2)+0.081 \times(3)+$ $1.02 \times(4)-2.13 \times(5)+0.15 \times(6)+1.23(7)-23.1(8)-5.42 \times(11)$ $+22.27 \times(12)+0.25(13)+0.45(14)-0.02 \times(21)+0.11 \times(23)$

$+1.25 \times(24)-7.21 \times(25)+1.25(26)+0.05(33)$

TABLE II: NORMAL MODEL

\begin{tabular}{ccccc}
\hline \hline \multirow{2}{*}{ Model } & R2 & $\begin{array}{c}\text { Adjusted } \\
\text { R2 }\end{array}$ & F test & significance \\
\hline 1 & .612 & .603 & 20.145 & .000 \\
\hline \hline
\end{tabular}

B. Economic Model (stepwise regression)

$\mathrm{WTP}=4285.03+16.84 \times(2)+10.72 \times(4)-0.81 \times(23)+$ $0.06 \times(31)$

The Numbers of ( ) is followed as Table I.

TABLE III: ECONOMIC MODEL

\begin{tabular}{ccccc}
\hline \multicolumn{5}{c}{ TABLE III: ECONOMIC MODEL } \\
Model & R2 & $\begin{array}{c}\text { Adjusted } \\
\text { R2 }\end{array}$ & F test & significance \\
\hline 1 & .690 & .645 & 16.330 & .000 \\
\hline \hline
\end{tabular}

The mean of the price that respondents are willing to pay (WTP) for metropolitan sustainable water use is NT 1,601 per year, and the values through $\mathrm{Eq}(1)$ and $\mathrm{Eq}(2)$ are NT\$ 1604 per year and NT\$ 1,607 per year (about US\$50 per year). The three results are very similar and the models are suitable for predict (The $\mathrm{R}$ square values for the equations are 0.61 and 0.69 ).

The mean of the price that respondents are willing to pay (WTP) for maintaining the same using level without changing habits is NT\$1620 per year (about US\$50 per year). In addition, the mean of the price those respondents are willing to pay (WTP) for cultural landscape facilities are NT\$3,359 per year (about US\$ 101 per year). Based on the three WTP results, it shows that the respondents expect not only keep the same life quality, but also like to pay more for better cultural landscape use. The original life style and cultural landscape facilities are not enough to support their need. 


\section{CONCLUSION}

To sum up, the policy acceptance for cultural landscape use at Miaoli are general higher than before, and it means they have better preference for environmental issues and try to accept some new ideas, such as the new cultural landscape tour development and the heritage re-use policy, for the sustainable future, even they may meet some different and uncomfortable situations. In addition, the perceptions in different areas are different with the different demographic structure during the study process.

For the present policy, most of respondents identify that the government need pay more attention for the improvement of related works and the efficiency, and more than $70 \%$ people report the government cannot show the enough information to gain the public supporting by mass media. In terms of public, they expected the cultural landscape use was more cautious, but the practical situation is contradictory. It is able to explain the score of policy satisfaction is relatively lower than others, though the respondents show the conservation and development issues have owned more improvement in the couple of years. In addition, they might know the plan of cultural landscape use well for local government, and some places had been worse tourism quality.

Based on the WTP, the result shows the respondents are able to pay more for the cultural landscape use, and the payment may be located on even one-tenth annual income. In other words, people are willing to spend more money to ensure more tour diversity, but the more details of policy information from government are needed.

\section{REFERENCES}

[1] D. Cosgrove, Social Formation and Symbolic Landscape, London: Croom Helm., 1984

[2] D. Demeritt, "The nature of metaphors in cultural geography and environmental history," Progress in Human Geography, vol. 18, no. 2, 1994, pp.163-185.

[3] L. K. Mapping, ""new" geographies of religion: Politics and poetics in modernity," Progress in Human Geography, vol. 25, no. 2, 2001, pp. 211-233.
[4] V. Coleman, Cultural Landscapes Chaarette, NSW Heritage Office, 2003.

[5] M. Brinkhuijsen, "Legible landscapes: The use of narratives in landscape design for leisure and tourism in Dutch cultural landscapes," presented at the ASA Conference Thinking through Tourism, Panel on Landscape Narratives, 2007.

[6] M. Brinkhuijsen, H. D. Jong, and R. Schröder, "Leisure and landscape: Trends and impacts, facts and figures," Helpdeskvraag 1094,19 januari.2007.

[7] V. Paul, Between the Landscape and Its Other, Johns Hopkins.

[8] S. V. C. Wantrup, "Capital returns from soil-conservation practices," Journal of Farm Economics, vol. 29, 1947, pp. 1188-1190.

[9] W. M. Hanemann, "Valuing the environment through contingent valuation," The Journal of Economic Perspectives, vol. 8, no. 4, 1994, pp. 19-43.

[10] T. Schelling, "The life you save may be your own," In Chase, S. (Ed.), Problems in Public Expenditure Analysis, Washinton, D. C.: Brooklings Institution, 1968, pp. 3-17.

[11] P. R. Portney, "The contingent valuation debate: Why economists should care," The Journal of Economic Perspectives, vol. 8, no. 4, 1994, pp. 3-17.

[12] R. R.Thawale, A. Uwarkar, and S. K. Singh, "Resource conservation through land treatment of municipal wastewater," Current Sci., 2006, vol. 90, no. 5, p. 704.

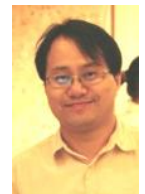

Shih-Chung Lu is a assistant professor in the Department of Architecture and Landscape Design, Nanhua University, Taiwan. He owned the BSc. and MLA in Tunghai University, Taiwan. He joined the PhD program in the Department of Horticulture and Landscape, University of Reading, England. Then, he went back Taiwan to develop his academia. He took the project manager in Taiwan environmental foundation and the Chi-Yung Landscape Ltd. After 2004, he got the teaching position in the Chienkuo Technology University, Taiwan, and he was promoted as an assistant professor in 2010. His research interests focused on the cultural landscape, low-carbon evaluation, and sustainable landscape management.

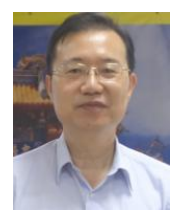

Kuei Yang Wu is currently a professor in the Department of Architecture and a dean of the College of Design at National United University, Taiwan. He received M.Sc. from the Department of Architecture, Tunghai University, Taiwan, and Ph.D. from the Department of Civil Engineering, National Central University, Taiwan. In 2003, he founded the Department of Architecture and became the chairman of the Department, National United University, Taiwan. In 2014, he also founded the College of Design and became the Dean of the College of Design. He has highly research interests in architectural design method, architecture planning, construction management and Environment and sustainable community development. 